\title{
La Masacre de los \\ Inocentes: una \\ aproximación desde la materialidad a la obra de Antonio Berni
}

\section{Artículo de investigación}

\section{Malena Wasserman}

Centro de Investigación en Arte, Materia y Cultura, IIAC-UNTREF - Argentina malewasserman@gmail.com

Recibido: 21 de junio de 2019 Aprobado: 25 de julio de 2019

Cómo citar este artículo: Wasserman, Malena (2020). La Masacre de los Inocentes: una aproximación desde la materialidad a la obra de Antonio Berni. Calle 14: revista de investigación en el campo del arte 15(28). pp. 282-291. https://doi.org/10.14483/21450706.16266

\section{(2) (1)}

https://creativecommons.org/licenses/by/4.0/deed.es 


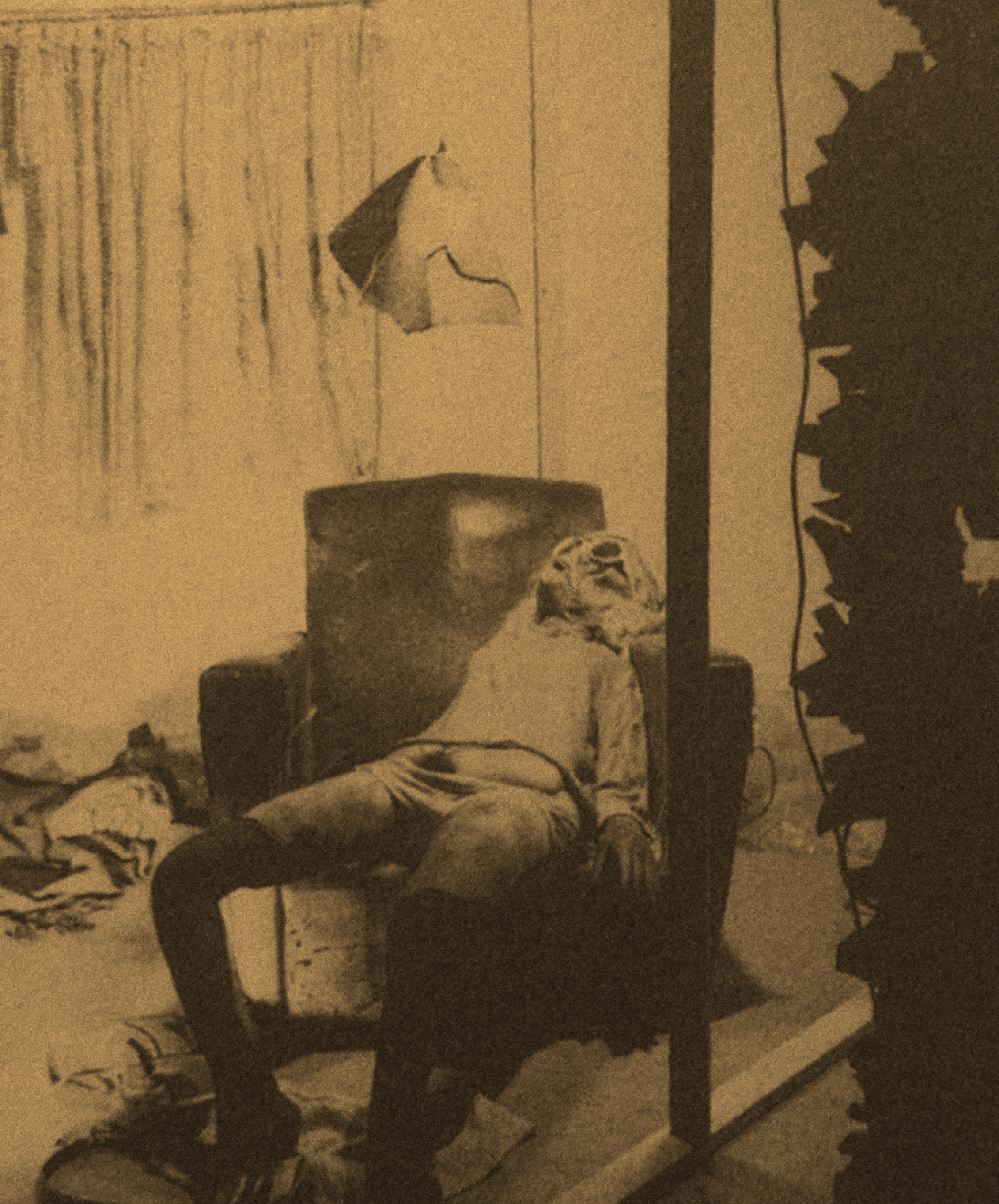




\section{Resumen}

Este artículo se propone recorrer algunos de los conceptos que vertebran el pensamiento de Aby Warburg (1866-1929) para, a partir de sus claves metodológicas, poder profundizar en la interpretación de la obra artística de Antonio Berni producida entre los años 50 y 80 . Es durante este período que el artista incorpora una variedad de materiales y objetos al espacio de representación que le otorgan un carácter distintivo al mismo. Recuperar ciertas herramientas conceptuales de Warburg y aplicarlas sobre un caso en particular como fue la instalación La Masacre de los Inocentes realizada por el artista rosarino en París entre 1971 y 1972, nos va permitir ahondar en la riqueza enunciativa que condensan estas obras bernianas en su dimensión material.

\section{Palabras clave}

Materialidad; arte; modernidad; Antonio Berni.

The Massacre of the Innocents: An Approach from Materiality to the Work of Antonio Berni

\section{Abstract}

This article sets out to explore some of the concepts that underpin Aby Warburg's thinking (1866-1929) so that, based on their methodological keys, they allow us to deepen the interpretation of Antonio Berni's artistic production between the 1950s and 1980s. It is during this period that the artist incorporates a variety of materials and objects into the space of his representation that give it a distinctive character. Recovering certain conceptual tools from Warburg and applying them to a particular case such as the installation The Massacre of the Innocents created by the artist from Rosario in Paris between 1971 and 1972, will allow us to delve into the enunciative wealth that these Berninian works condense in their material dimension.

\section{Keywords}

Materiality; art; modernity; Antonio Berni.

Le massacre des innocents : une approche à partir de la matérialité à l'œuvre d'Antonio Berni

\section{Résumé}

Cet article se propose d'explorer certains des concepts qui sous-tendent la réflexion d'Aby Warburg (1866-1929) afin que, à partir de leurs clés méthodologiques, ils nous permettent d'approfondir l'interprétation de la production artistique d'Antonio Berni entre les années 1950 et 1980. C'est durant cette période que l'artiste incorpore une variété de matériaux et d'objets dans l'espace de sa représentation qui lui confèrent un caractère distinctif. Récupérer certains outils conceptuels de Warburg et les appliquer à un cas particulier comme l'installation Le Massacre des Innocents réalisée par lsartiste de Rosario à Paris entre 1971 et 1972, nous permettra de plonger dans la richesse énonciative que ces œuvres de Berni condensent dans leur dimension matérielle.

\section{Mots clés}

Matérialité ; art ; modernité ; Antonio Berni. 


\section{Resumo}

Este artigo se propõe explorar alguns conceitos que sustentam o pensamento de Aby Warburg (1866-1929) para, a partir de suas chaves metodológicas, poder aprofundar na interpretação da obra artística de Antonio Berni produzida ente os anos de 50 e 80 . É durante este período que o artista incorpora uma variedade de materiais e objetos ao espaço de representação que lhe atribuem um caráter distinto. Recuperar certas ferramentas conceituais de Warburg e aplicálas sobre um caso particular como foi a instalação La Masacre de los Inocentes realizada pelo artista rosarino em Paris entre 1971 e 1972, nos vai permitir aprofundar na riqueza enunciativa que condensam estas obras bernianas em sua dimensão material.

\section{Palavras chave}

Materialidade; arte; modernidade, Antonio Berni.

\section{Llanga wañuchiskakunata kai kilkako pangapi Antonio Berni}

\section{Maillallachiska}

Pangapi krikaspa iuiachiku unaimanda kai watapi 1866-1929 Ohasa Tukuikunata munaku kawakingapa kai ruraikuna llakispa nanga wanuskakunamanda,Ruraska sug warmiiacha rosario suti kai watakunapi 1971- 1972 nunaku kawachinga Nukanchipa Achka llukaskata pangapi kilkaspa.

\section{Rimangapa Ministidukuna}

Materialidad; arte; kunauramanda; chasa suti puna. 


\section{Introducción}

El siguiente trabajo se articula con el proyecto "Explosión matérica. Estrategias estéticas, técnicas y materiales en la obra de Antonio Berni entre los '50 y los '80" (PICT 2015-0440), que se desarrolla en el centro MATERIA de la Universidad Nacional Tres de Febrero bajo la dirección de Gabriela Siracusano con subsidio del FONCyT. Dentro de dicho proyecto se trabaja desde una perspectiva interdisciplinaria con un equipo integrado por químicos, restauradores e historiadores del arte.

Como sabemos, los aportes de Warburg representan un giro dentro de la historia del arte en el modo en que entendemos las imágenes. Sus investigaciones proponen un enfoque teórico-metodológico novedoso al incorporar fuentes no tradicionales y todo tipo de testimonios capaces de arrojar luz en la interpretación y análisis del significado de las obras. En sus trabajos iniciales el investigador hamburgués se centró en la figura de Botticelli y la producción artística del Quatroccento, a partir de la cual detectó una constante en relación al modo en que estos artistas florentinos retomaban la tradición clásica antigua. El concepto de Nachleben le permitió plantear el modo particular en que lo antiguo, o la experiencia anímica antigua, era recuperada por la cultura del Renacimiento luego de siglos cristianos donde había permanecido eclipsada (Burucúa, 2003, pp. 14-15).

Para dar cuenta de esta supervivencia de la tradición clásica Warburg rastrearía en los documentos, tanto visuales como escritos, disponibles en la cultura florentina de principios del siglo XV a partir de los cuales sería posible reconstruir la circulación de representaciones pictóricas y literarias provenientes del mundo antiguo. Asimismo, estas búsquedas le permitieron revelar la compleja trama en que la producción de estas imágenes se ubicaba y en la cual habrían intervenido una multiplicidad inimaginable de actores, objetos, tradiciones y conocimientos (Burucúa, 2003, p. 19).

Warburg identificaría la recurrencia a un repertorio de posturas y gestos que él advirtió como "tratamiento de los motivos accidentales en movimiento" (Warburg, 2005, p. 96) provenientes del mundo clásico y que daban cuenta de esta fuente de inspiración para los artistas florentinos. Es precisamente en el movimiento, en los drapeados, en los cabellos, en la ornamentación de estas composiciones que Warburg pudo reconocer el síntoma de una vuelta al aspecto más agitado o desenfrenado de la emocionalidad pagana. En sus propias palabras: "La forma en que las figuras de la Antigüedad resucitaron antes los ojos de la sociedad italiana no fue la de los modelos de yeso, sino de la abigarrada magnificencia del desfile festivo donde el amor pagano por la vida había encontrado su refugio en el mundo popular" (Warburg, 2005, p. 128).

Sobre la base de estas ideas, este trabajo se propone, entonces, pensar de qué modo el concepto de Nachleben nos puede ayudar a comprender el uso de las imágenes y su materialidad en la producción plástica de Antonio Berni. En primera instancia, resulta importante destacar que se trata de un artista que, desde sus inicios, comprendió la capacidad de denuncia política que poseen las imágenes. En este sentido es que trabajó, a lo largo de toda su trayectoria, en las posibilidades de una estética realista que poseyera la fuerza y eficacia para trasmitir los grandes dramas que aquejaban a la cultura de su época.

Uno de los recursos retóricos a los que acude Berni para conseguirlo radica en la utilización de un repertorio visual que cuenta con una larga tradición y por lo tanto acumula en su historia profundas figuras simbólicas. La alusión a la iconografía religiosa fue algo habitual a lo largo de toda su producción. Mucho se ha insistido desde la historiografía argentina (Amigo, 2010; Sánchez, 2005; Pacheco, 2005) que esta recurrencia al repertorio tradicional católico operaba a favor de la trasmisión del contenido social y político de sus imágenes.

\section{La Masacre de los Inocentes}

En esta oportunidad nos proponemos trabajar sobre una obra particular del artista rosarino. Se trata de la instalación La Masacre de los Inocentes, la cual formó parte de una retrospectiva que el Museo de Arte Moderno de París (MAMVP) llevó a cabo entre noviembre de 1971 y enero de 1972. La instalación mencionada constituyó el trabajo más reciente dentro de esta exposición, ya que fue realizado en su taller parisino especialmente para esa ocasión.

El título de la obra hace referencia a un suceso bíblico del Nuevo Testamento que figura en el Evangelio de San Mateo y se conoce como la matanza de los santos inocentes. Como sabemos, dicho relato narra las acciones que ejecutó Herodes al enterarse, a través de los sabios de Oriente, de la llegada de Jesús de Nazaret, sin que ellos pudieran determinar el lugar específico de su nacimiento. La necesidad de deshacerse del recién nacido por la amenaza que este podía representar a su poder 
llevó a Herodes a actuar con una violencia despiadada. En el Evangelio se describe de la siguiente manera:

Entonces Herodes, al ver que había sido burlado por los magos, se enfureció terriblemente y envió a matar a todos los niños de Belén y de toda su comarca, de dos años para abajo, según el tiempo que había precisado por los magos. Entonces se cumplió el oráculo del profeta Jeremías: «Un clamor se ha oído en Ramá, mucho llanto y lamento: es Raquel que llora a sus hijos, y no quiere consolarse, porque ya no existen». (Mateo, II, 16-18).

De más está decir entonces que esta iconografía cuenta con una larga historia. La brutalidad y la enorme carga emotiva contenida en el episodio hacen que, como veremos, la fórmula expresiva contenida en esta iconografía se haya vuelto eficaz para describir las tragedias más oscuras de la humanidad. Sobre todo, en cuanto permite subrayar la inocencia de sus víctimas, por tratarse de bebés indefensos, en una relación totalmente desigual que se presenta ante la figura del agresor.

Este contraste ya se advierte en un manuscrito iluminado del siglo $X$ el cual pertenece al Codex Egberti. En este ejemplo es posible empezar a definir las dos cargas dramáticas en contraposición que componen la escena. Por un lado, la actitud destructiva de los soldados en una condición de superioridad sobre sus víctimas vulnerables y sin posibilidad de defenderse, pero también la expresión de desesperada angustia de las madres al ver morir a sus hijos y no poder hacer nada por impedirlo.

Como bien ha señalado el profesor Burucúa, es a partir de la Edad Media que el culto de los santos inocentes registra un apogeo en su vitalidad. La multiplicación de representaciones pictóricas sobre esta iconografía se ve en aumento, especialmente a partir del Trecento, al convertirse en el escenario predilecto para expresar el "desgarramiento emocional sin límites", como diría Burucúa (2014, p. 102). Un ejemplo de este período es el que Giotto pinta en la Capilla Scrovegni de Padua. En el centro de la composición, nuevamente como en la representación anterior, la expresión amenazadora de uno de los soldados de Herodes con el brazo en alto blandiendo el arma para arrancar al niño de los brazos de su madre. Este gesto se va a replicar en innumerables ejemplos para vehiculizar la potencia guerrera del soldado victorioso. En una de las pinturas que Doménico Ghirlandaio realiza para la capilla Tornabuoni en Santa María Novella el gesto vuelve a repetirse. Va a ser sobre esta obra que el propio Warburg advierte:
Si observamos con atención el apasionado dramatismo de las mujeres y soldados en lucha, en un primer momento sus gestos parecen espontáneos, pero terminan revelando sus fuentes romanas, el pathos guerrero del relieve de Constantino [...] Mediante tipos patéticos [Pathosformeln] intentó insuflar en la prosa de los Tornabuoni el estilo más elevado de un ideal movimiento antiguo pues, precisamente en aquella época los espíritus liberados de la gestualidad patética antigua no consentían mantenerse absortos a la distancia.

Warburg utiliza el concepto de Pathosformel para referirse a estas fórmulas expresivas provenientes de la Antigüedad que son retomadas por artistas como Boticelli o Ghirlandaio. Estas, ancladas en la gestualidad, poseen la fuerza para transmitir una experiencia primaria ancestral y así provocar una respuesta emotiva.

Ahora bien, en relación con las distintas herramientas discursivas o pictóricas utilizadas a lo largo de la historia para representar masacres, Burucúa señala una dificultad que se advierte en las representaciones del siglo XX. La magnitud de los horrores de la experiencia contemporánea hace que las viejas fórmulas se volvieran inadecuadas, por lo que resultaría necesario explorar en nuevos horizontes formales para poder dar cuenta de los hechos (Burucúa, 2014, p. 179).

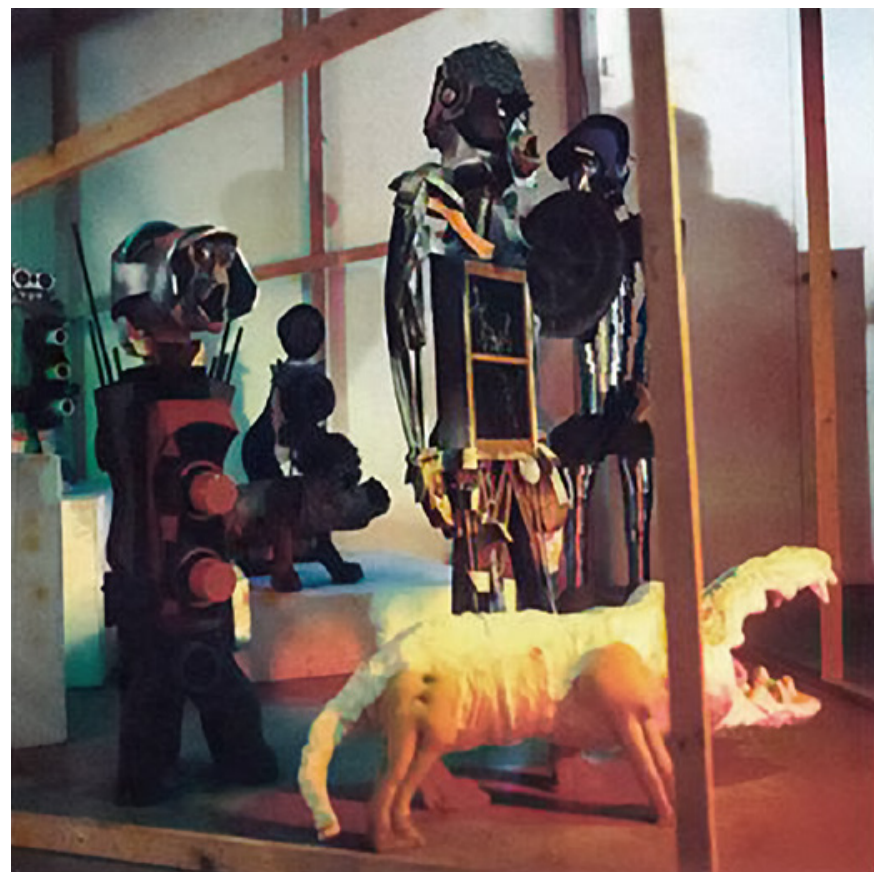

Imagen 1. Antonio Berni, La Masacre de los Inocentes, Museo de Arte Moderno de París. 1971. Instalación. 


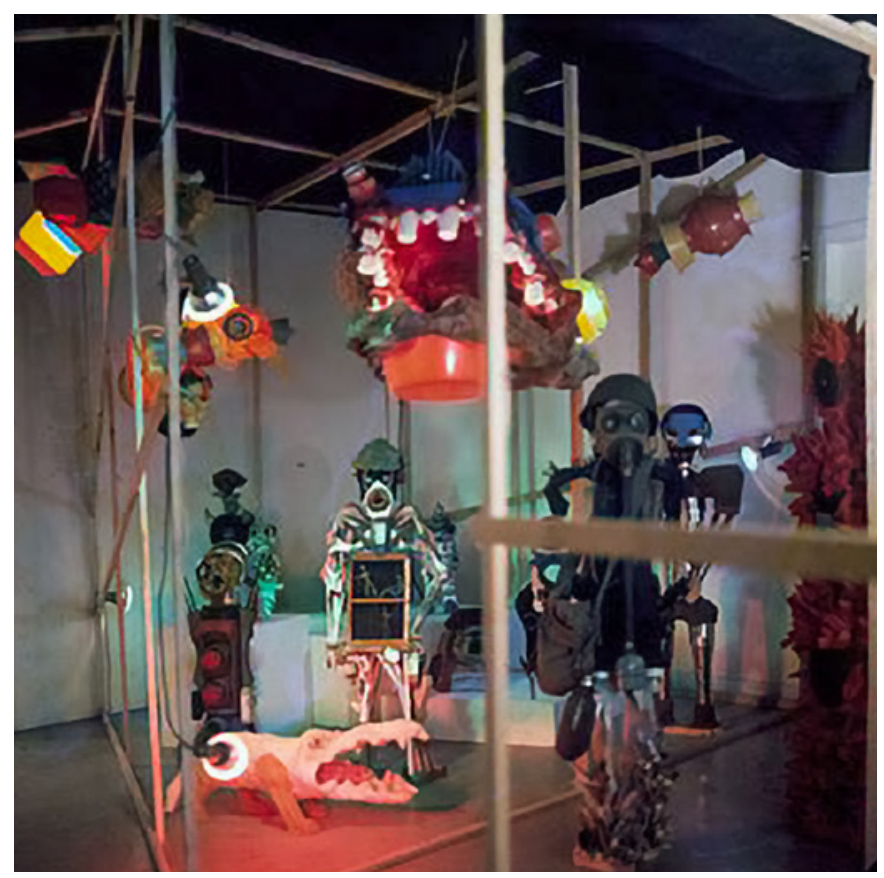

Imagen 2. Antonio Berni, La Masacre de los Inocentes, Museo de Arte Moderno de París. 1971. Instalación.

Si pensamos en la obra de Berni mencionada anteriormente, resulta interesante preguntarnos de qué modo el artista consigue una actualización de este relato bíblico, qué aspectos decide recuperar sobre su tradición visual y qué estrategias utiliza para conseguir una renovación de dicha iconografía.

Gracias a los registros fotográficos de la exposición (Imagen 1) es que podemos reconstruir cómo se disponía esta instalación. En este sentido, podemos advertir que la obra estaba compuesta por un ejército de robots que tomaban cuerpo a partir del ensamble de distintos materiales de desecho de la sociedad industrial de consumo. El mismo artista los denominó como "construcciones polimatéricas" (Oliveras, 2001, p. 8). Mediante una estética experimental y agresiva, los antiguos soldados de Herodes en esta ocasión adquieren un aspecto mecanizado. Conforman un dispositivo de destrucción terrorífico que evoca los desastres que atormentan al hombre contemporáneo. En una entrevista realizada para la revista Panorama, Berni alude a su obra como "la expresión de la agresividad guerrera, de las exaltaciones de la soldadesca, del asalto policial sin discriminación, del terror intelectual que se agita sin piedad sobre familias, trabajadores, niños sin defensa".

A su vez, y gracias a estas fotografías de la época (Imagen 2), podemos advertir que este ejército se integraba además por unas criaturas voladoras que colgaban de la parte superior de la estructura y, de este modo, quedaban suspendidas en altura. La decisión de incluir estos personajes aéreos cobra sentido si reparamos en las características que tomaron las masacres en este contexto histórico. El ataque aéreo en el siglo XX se convierte en una amenaza concreta. Pensemos en los bombardeos sobre Londres por parte de la Alemania nazi, en las explosiones nucleares de Hiroshima y Nagasaki o en el uso que se hizo del paracaidismo durante la Guerra Fría con el objetivo de conseguir operaciones sorpresivas sobre el enemigo. No está de más mencionar que todas estas escenas provenientes de una experiencia aérea fueron registradas y reproducidas infinidad de veces, por lo que habían pasado a formar parte de un repertorio visual común para la sociedad de aquel entonces.

Asimismo, como se observa en una de las fotografías tomadas en el taller parisino de Berni (Imagen 3) es que podemos reponer la presencia de varios bebés de plástico deteriorados junto a los soldados, lo cual alude obviamente al sacrificio de las víctimas inocentes. A su vez, en las fotografías que acompañan la entrevista del artista en la revista Panorama (Imagen 4) se advierte que la escena se completaba con un personaje femenino. Al costado se recreaba una habitación con una lámpara que iluminaba directamente a esta mujer que yacía desplomada sobre un sillón.

Su expresión corporal nos permite vincularla con una figura que suele aparecer en las representaciones de masacres: la madre resignada o abatida por los horrores que le ha tocado vivir. Podemos pensar en algunos ejemplos de este personaje, pasivo y derrotado, en obras como La Masacre de los Inocentes de Luca Giordano o La Masacre de Chios de Eugene Delacroix. Berni recupera su fórmula expresiva y consigue evocar toda esta carga emotiva que supone su presencia en la escena.

En el caso de la mujer de la instalación de Berni, la misma llevaba lentes oscuros, una peluca, medias de liga y ropa interior que dejaba al descubierto parte de su vello púbico. Su aspecto ultrajado también connota el rol histórico que ha cumplido la mujer durante masacres o conflictos bélicos como parte de un botín de guerra. Las violaciones por parte de los soldados sobre niñas y mujeres del bando enemigo han funcionado como una práctica común para sembrar el terror y detentar la impunidad, incluso en los genocidios del siglo XX.

Por otra parte, la obra era acompañada por un texto en francés que el mismo artista había redactado y en 


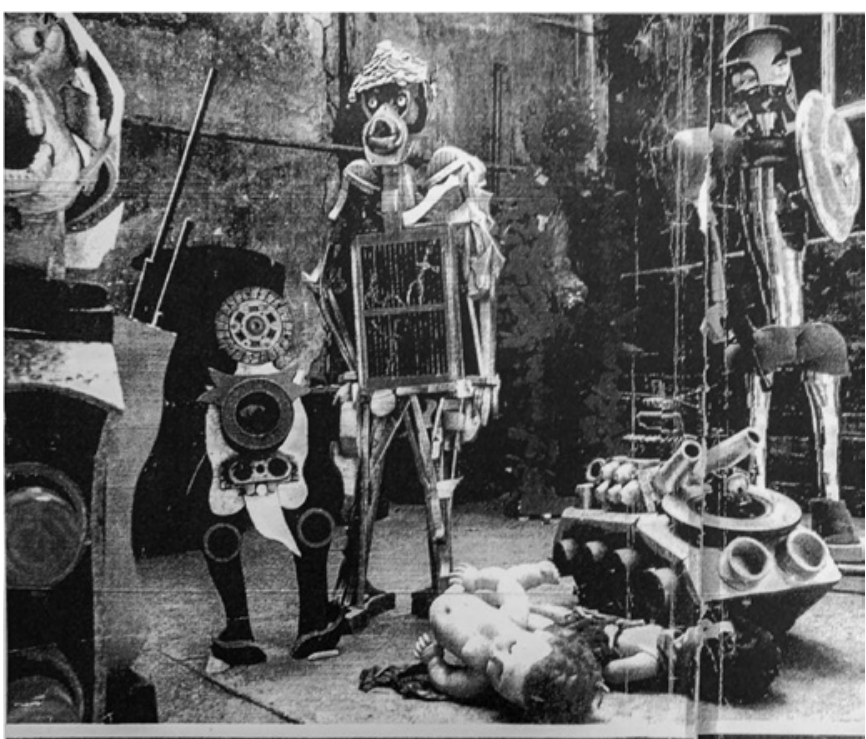

LAMASAFIE DELOSLOHEIIIS

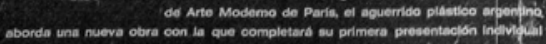

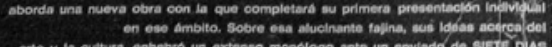

Imagen 3. "Antonio Berni, La Masacre de los Inocentes", Revista Siete Días, Año 5, №224, Buenos Aires.

el cual presentaba los propósitos políticos y estéticos de la instalación. En esta suerte de manifiesto teórico él hacía referencia a la tradición del pesebre cristiano y al gran poder de evocación que desde la Edad Media y hasta el siglo XIX había representado para la sensibilidad popular. Berni buscaba recuperar dicha significación en su Masacre de los inocentes al perpetuar una tradición que pasara "de lo religioso a lo político y de lo sagrado a lo cotidiano". La decisión de Berni de presentar imágenes corporales, que se desarrollan en las tres dimensiones, le permitió construir un clima verdaderamente perturbador e inquietante en el que también se veía envuelto el espectador.

Dos de los robots que integraron la instalación (Imagen 5) actualmente forman parte del patrimonio del Museo Nacional de Bellas Artes gracias a una donación del hijo del artista realizada en el año 2004. Tal como las figuras de los soldados de las representaciones mencionadas anteriormente, el primero de estos soldados-robots también exhibe el gesto con el brazo en alto en actitud amenazante. Esta vez el arma que sostiene no es una espada como lo hacían los otros soldados. La artillería punzante con la que ataca este personaje nace de un desecho industrial, un objeto que pudimos identificar como una bomba de freno de un automóvil. Es a partir de un uso muy particular del collage y del assemblage de materias varias

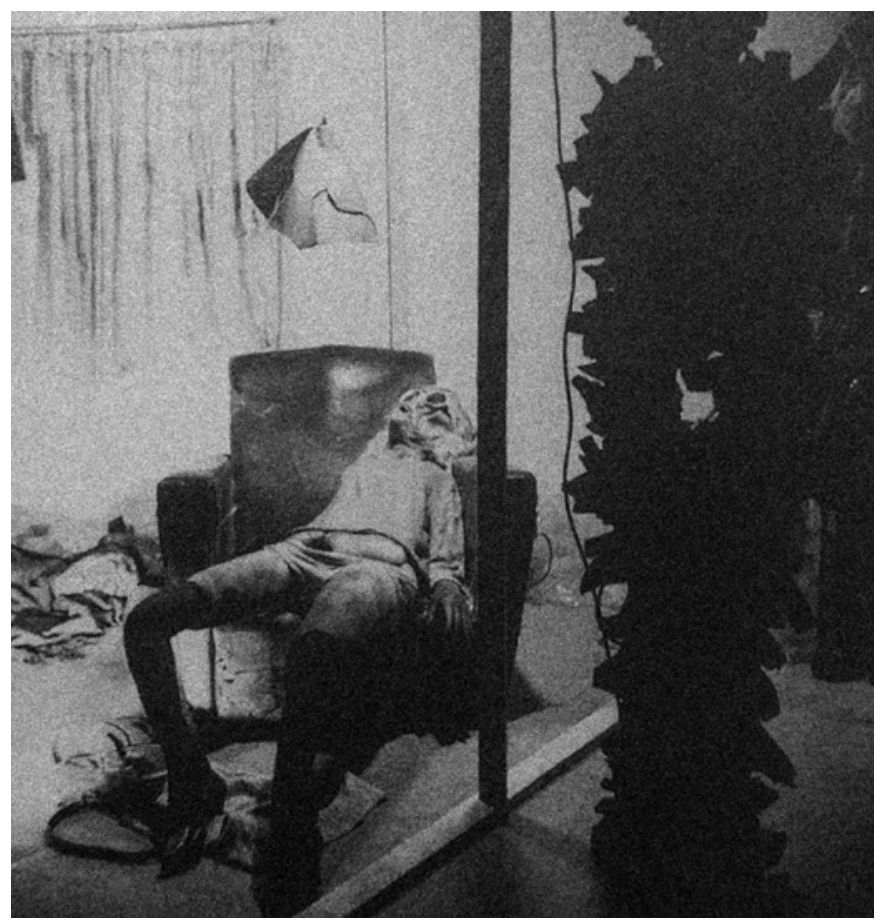

Imagen 4. Antonio Berni, La Masacre de los Inocentes, Museo de Arte Moderno de París. 1971. Instalación.

que Berni consigue reeditar y reactivar esta antigua fórmula expresiva. La expresión del pathos guerrero se hace presente mediante esta reconocible gestualidad ancestral. Pero en esta oportunidad Berni articula el gesto dramático con una propuesta vehiculizada en su dimensión material. En una entrevista durante su estadía en Paris Berni definió a sus materiales como "los rezagos de un mundo tecnificado, los excrementos de la sociedad de consumo que vivimos".

Esta bomba de freno no es el único elemento proveniente del mundo automotriz que el artista utilizó. Tanto el objeto que constituye la parte media de este personaje como la cabeza del otro son dos componentes -el disco y la prensa - del embrague de un antiguo modelo de automóvil de la marca francesa Citroën.

En el caso del primero, el objeto que tiene atornillado en su parte superior es un carburador de doble boca, a partir del cual se define su cabeza. En un motor, los dos discos metálicos ubicados en cada orificio giran sobre su propio eje para regular la combinación de aire y combustible mediante un sistema mariposa. La elección de esta pieza cobra un significado especial si se advierte que el movimiento propio del funcionamiento de esta parte del motor reproduce la acción del parpadear de los ojos del personaje. A través de una palanca ubicada a la derecha es posible abrir y cerrar las 

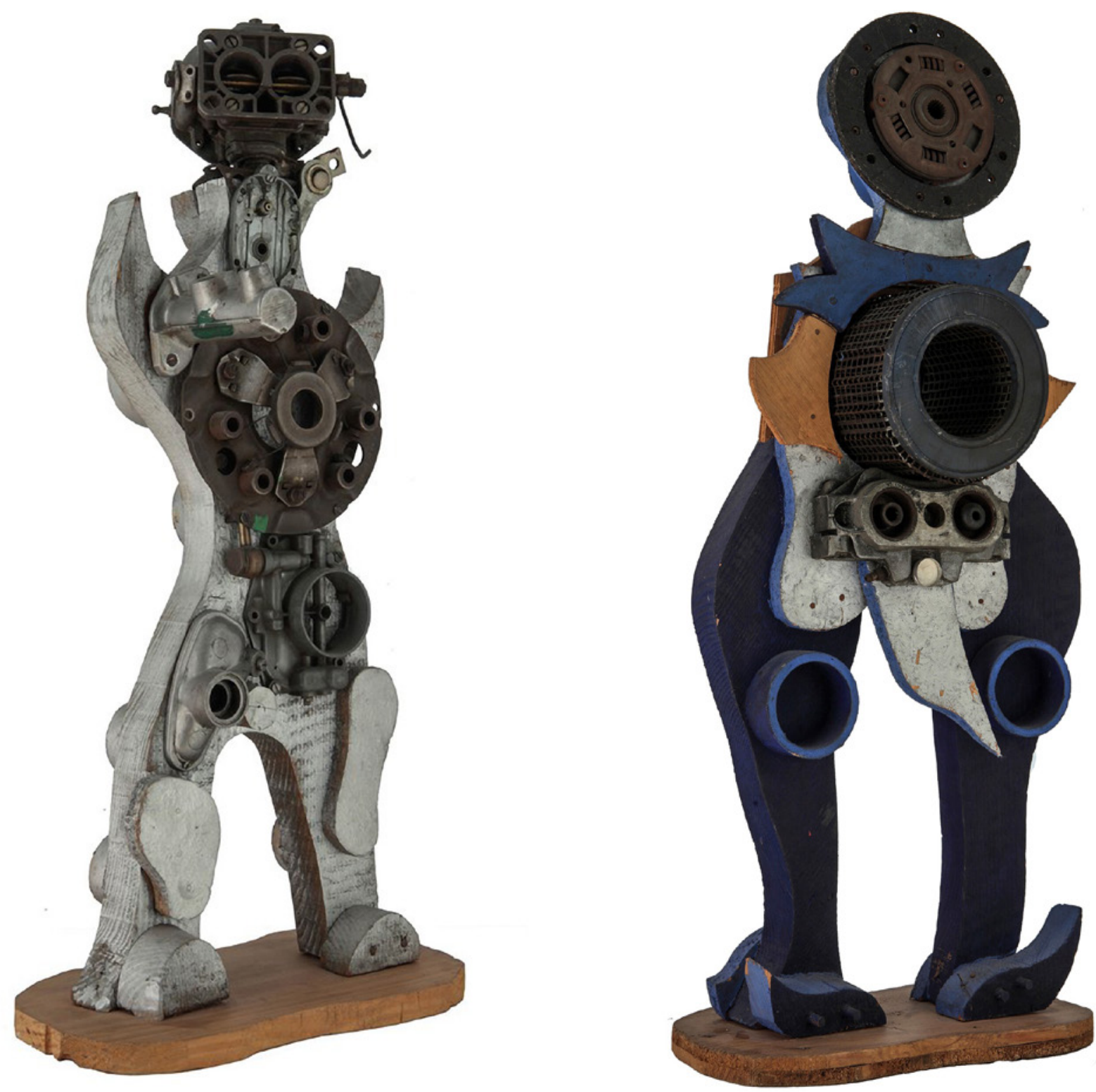

Imagen 5. Antonio Berni, Robot, La Masacre de los Inocentes, Museo Nacional de Bellas Artes, Buenos Aires, 1971. Construcción polimatérica.

válvulas del mecanismo. De esta manera, Berni consigue imprimir el gesto humano sobre el rostro mecanizado.

Este ejército de Herodes contemporáneo toma cuerpo a partir del ensamble de objetos que operan como fragmentos de un mundo industrializado que avanza de manera destructiva sobre los más desfavorecidos. Pensemos por aquellos años en las víctimas inocentes de la Guerra de Vietnam, en los trabajadores en manos del control policial durante las huelgas obreras, o incluso como menciona el artista en su entrevista en la revista Siete Días, en las víctimas del accionar de la guerrilla urbana.

\section{Conclusión}

Para concluir deseamos enfatizar que los objetos que Berni seleccionó en esta obra se encuentran anclados en un contexto cotidiano, y funcionan dentro del espacio de representación como testimonios materiales de las posibilidades de existencia de las masacres reales de su tiempo. De esta manera, recuperó la memoria de dichos materiales y consiguió manipular en un sentido narrativo la riqueza simbólica de cada uno de los objetos que utiliza.

A su vez, en esta instalación Berni articuló todo un arsenal de recursos plásticos y discursivos con los que 
él ya venía ensayando en la producción de la década del 60. En esta oportunidad, los puso a disposición de un complejo mecanismo visual y expresivo, que se apoya en una antigua tradición. A partir de este mecanismo y de un uso inteligente de los propios materiales de su época es que pudo denunciar las atrocidades de su mundo.

\section{Referencias}

Amigo, Roberto (2010. Berni: narrativas argentinas. Buenos Aires: Museo Nacional de Bellas Artes.

Appadurai, Arjun (1986). The Social Life of Things. Cambridge: Cambridge University Press. https://doi.org/10.1017/CB09780511819582

Burucúa, José Emilio (2003). Historia, arte, cultura. De Aby Warburg a Carlo Ginzburg. Buenos Aires: FCE.

Burucúa, José Emilio y Nicolás Kwiatkowski (2014). "Cómo sucedieron estas cosas" Representar masacres y genocidios. Buenos Aires: Katz Editores. https://doi.org/10.2307/j.ctvm7bdbf

Dolinko, Silvia (2012). Arte Plural. El grabado entre la tradición y la experimentación, 1955-1973. Buenos Aires: Edhasa.

Giunta, Andrea (2001). Vanguardia, internacionalismo y política: Arte argentino en los años sesenta. Buenos Aires: Paidós Ibérica Ediciones SA.
Gombrich, Ernst (2002). Aby Warburg, An Intelectual Biography. Oxford: Phaidon.

Oliveras, Elena (2001). Los monstruos de Antonio Berni. Buenos Aires: Centro Cultural Borges.

Pacheco, Marcelo (2005). "Antonio Berni: un comentario rioplatense sobre el muralismo mejicano", en: Berni y sus contemporáneos: correlatos. Buenos Aires: Museo de Arte Latinoamericano de Buenos Aires.

Plante, Isabel (2013). Argentinos en París. Arte y viajes culturales durante los años sesenta. Buenos Aires:

Edhasa.

Sánchez, Julio (2005). "El peregrino y la diosa blanca", en Berni y sus contemporáneos: correlatos. Buenos Aires: Museo de Arte Latinoamericano de Buenos Aires. Siracusano, Gabriela (2005). El poder de los colores. De lo material a lo simbólico en las prácticas culturales andinas, Buenos Aires: FCE.

Warburg, Aby (2005). El renacimiento del paganismo: aportaciones a la historia cultural del Renacimiento europeo. Madrid: Alianza Editorial. 